\title{
Detection of nickel in nail samples of poultry farm workers
}

\author{
Moneeza Abbas*, Ayesha Abbas, Amina Abrar and Sofia Nosheen \\ Environmental Science Department, Lahore College for Women University, Lahore-Pakistan \\ *Corresponding author's email: moneeza.rana@gmail.com \\ Citation \\ Moneeza Abbas, Ayesha Abbas, Amina Zafar and Sofia Nosheen. Detection of nickel in nail samples of \\ poultry farm workers. Pure and Applied Biology. Vol. 6, Issue 1, pp213-217.
}

http://dx.doi.org/10.19045/bspab.2017.60016

Received: 28/10/2016 Revised: 02/02/2017

Accepted: 09/02/2017

Online First: 11/02/2017

\section{Abstract}

Nickel content in nail samples of male poultry farm workers involved in manual feeding operations was detected using atomic absorption spectrophotometer (AAS). The nickel concentration in nail sample of poultry farm workers ranged from 0.53 to $6.10 \mathrm{mg} / \mathrm{l}$. Assessment of general health status of workers revealed that some workers had different kind of skin allergies and respiratory diseases like asthma due to unpredictable toxicity of nickel in their body owing to exposure to $\mathrm{Ni}$ during manual feeding operations.

Keywords: Nickel; Fingernails; Male worker; Atomic absorption spectrophotometer

\section{Introduction}

Due to rapid growth of economy and the sharp advanced trend lie in urbanization and industrial sector, the environmental concerns have become increasingly more important. So researchers are working on routes of exposure of heavy metals and of their toxicity. Great efforts are being made to mitigate the issues [1]. Nickel is used as the raw material in production non- ferrous alloys, stainless steel and super alloys. Nickel salts are widely used in electroplating. Nickel is also used in batteries, coins, and electronic products [2]. Nickel is largely used in manufacturing of household appliances [3]. Other than these uses nickel is added in some food supplements and one tablet of these supplements may contain several micrograms of nickel [4]. Major focus of poultry industry is to enhance the growth rate. Many of the metals are used in poultry feed well beyond the required amount to boost the weight of poultry animals [5]. Poultry feed also have nickel as one of the ingredients used to boost weight of poultry animals, and as starter, developer and grower. A study was conducted in Saudi Arabia to determine $\mathrm{Ni}$ content in poultry feed samples and was found in high amounts ranging from 0.45 to $3.26 \mathrm{mg} / \mathrm{kg}$ [6].

Poultry farm workers involved in handling of poultry feed can be exposed to nickel. Sources of nickel exposure can be ingestion, inhalation and skin contact. Manual handling of Poultry feed can increase the risk of nickel exposure though absorption by skin. Excessive amount of nickel in humans can have profound health effects including damage to kidneys, stomach, liver, immune system and reproductive system. Some studies also reported the dermatitis while lung cancer due to Ni exposure [7].

Nickel is a known carcinogenic metal and is an occupational pollutant. Some epidemiological studies have showing strong 
connection between exposure to nickel and great risk of lung cancer. Long term exposure to nickel can also lead to other health issues including developmental deficit in children, cardiovascular diseases, neurological deficits and high blood pressure [8]. A research study conducted by Macomber and Hausinger (2011) assessed nickel toxicity and obtained a multi-tiered toxic attack, as nickel produce metal inequality in the body leading to disturbance in enzyme regulation. Ultimately, results in the state of oxidative stress [9].

In typical diet only $1-10 \%$ of the ingested dietary $\mathrm{Ni}$ is absorbed; following absorption, $\mathrm{Ni}$ is transported in blood bound to serum albumin. Most of the absorbed $\mathrm{Ni}$ is excreted by the kidneys linked to complexes with low molecular weight and it is also lost through sweat and bile. It is not accumulated by any tissue in the body. Relatively high $\mathrm{Ni}$ concentrations were found in the thyroid and adrenal glands in comparison to other tissues When nickel is ingested or absorbed through the skin, it is transported to in blood bound to serum albumin. $\mathrm{Ni}$ is then excreted by kidney and can also lose thorough sweat and bile. It is not accumulated in body tissues except adrenal and thyroid glands [10]. Nickel determination in nail samples is the subject of interest because it assesses the nutritional status, systemic intoxication and environmental exposure [11].

Poultry farming is one of the largest industries in Pakistan. In Pakistan after textile industry Poultry farming and its processing has become second largest industry. In Pakistan and Asian countries Poultry farming culture is expanding Very rapidly. There were two types of common poultry houses the environment control house and open-side house. In the recent years the modern trend of environment control houses $(\mathrm{ECH})$ in poultry production has become a great revolution in poultry industry of Pakistan. Present study was conducted to analyze $\mathrm{Ni}$ in nail sample of poultry farm workers. The measurement of elements in nails was used as biomarker for exposure, for health care management purposes.

\section{Materials and methods}

General health care of worker (from whom nail samples were collected) was recorded through questionnaire. Nail samples were collected through random sampling method from workers working in different poultry farms. $0.05 \mathrm{~g}$ of nail samples was washed with nonionic detergent (TritonX-100) to remove dust particles following a standardized washing procedure [12]. The nails were also soaked in acetone to remove external contamination. Samples were rinsed five times with deionized water and dried in oven.

Dried nail samples were subjected to wet acid digestion with $10 \mathrm{ml}$ of 6: 1 mixture of concentrated nitric and perchloric acid. The sample solutions were diluted with $0.1 \mathrm{~N}$ nitric acid. After dilution samples were filtered [11]. Samples duplicate were tested on Atomic Absorption Spectrophotometer using hollow cathode lamp of nickel. The values of standard solution, references, absorbance and concentration were noted.

\section{Results and discussion}

Through survey and questionnaire it was observed that most of the workers suffered from various health problems like blood pressure, stress, skin infections and respiratory diseases like asthma. The main cause of these diseases may be the exposure to $\mathrm{Ni}$ at work place. The feed of chickens contained $\mathrm{Ni}$ as ingredient. The source of exposure to $\mathrm{Ni}$ was through direct contact with $\mathrm{Ni}$ in feed during feeding operations. Mainly in open-side poultry house manual feeding operations was the possible way of exposure. In Environment controlled shed workers were also exposed to $\mathrm{Ni}$ in feed 
during first week of feeding operations of newly grown chickens. The health status of workers was not satisfactory. Beside the poor health and poverty, lack of education and awareness also results in ill and stress full life of workers. The results of the quantitative analysis of finger nails for $\mathrm{Ni}$ was recorded according to the age groups and years of exposure. The nickel concentration in nail sample of poultry farm workers ranged from 0.53 to $6.10 \mathrm{mg} / \mathrm{l}$. The Figure 1 presented the mean concentration of $\mathrm{Ni}$ in different age groups of poultry farm workers. The mean concentration of nickel in different age group recorded was as following: $1.61 \pm 1.29 \mathrm{mg} / \mathrm{l}$ for age group $(15-25) ; 1.26 \pm 0.67 \mathrm{mg} / \mathrm{l}$ for age group (26$35) ; 1.76 \pm 0.9 \mathrm{mg} / \mathrm{l}$ for age group (36-45) and $1.25 \pm 0.9 \mathrm{mg} / \mathrm{l}$ for age group (46-55).

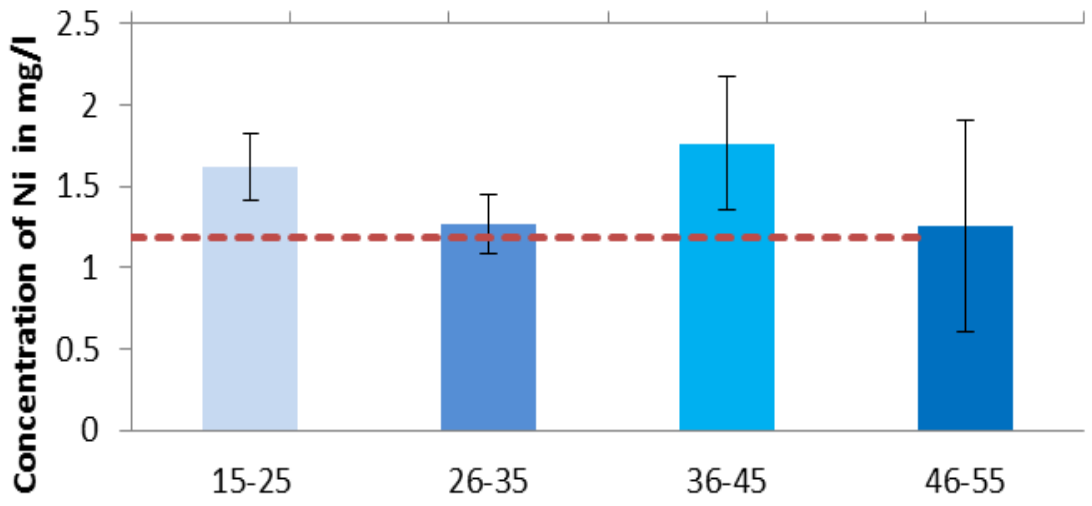

Concentration of nickel

- - - reference value of $\mathrm{Ni}$

Ni concentration in different age groups among poultry farm workers

Figure 1. Comparison of $\mathrm{Ni}$ concentration in different age groups among poultry farm workers

Relationship between the operational years and concentration was also studied it was observed that the Concentration of $\mathrm{Ni}$ in operational year were as followed: 1-5year was $1.27 \pm 0.8 \mathrm{mg} / \mathrm{l} ; 6$-10year was $1.95 \pm 1.0$ $\mathrm{mg} / \mathrm{l}, 11-15$ year was $1.75 \pm 1.27 \mathrm{mg} / \mathrm{l}$ and the operational year 16-20 the concentration of $\mathrm{Ni}$ was ranged from $3.68 \pm 2.17 \mathrm{mg} / \mathrm{l}$. Nickel concentration in nail sample of poultry farm workers was above the reference value [12] given by Gammelgaard et al. (1991) for nickel concentration in nails that is $1.19 \pm 1.61 \mu \mathrm{g} / \mathrm{g} \quad$ (Figure 2). The concentration of $\mathrm{Ni}$ in workers that had been working for 16-20 years was more than that of 1-5 years. As mean concentration of $\mathrm{Ni}$ in operational years $16-20$ was $3.68 \pm 1.25$ beyond the reference value and 1-5 years was $1.27 \pm 0.13$ it was also greater than the reference value. From assessment of health status it was revealed that cough and shortness of breath was the common disease among workers. Exposure to $\mathrm{Ni}$ also causes nausea, vomiting, abdominal discomfort, diarrhea, headache, cough and shortness of breath [13].It was also observed that workers developed some skin allergies on their hand and foot due to direct contact with nickel and absence of occupational health and safety programme in their work place. 


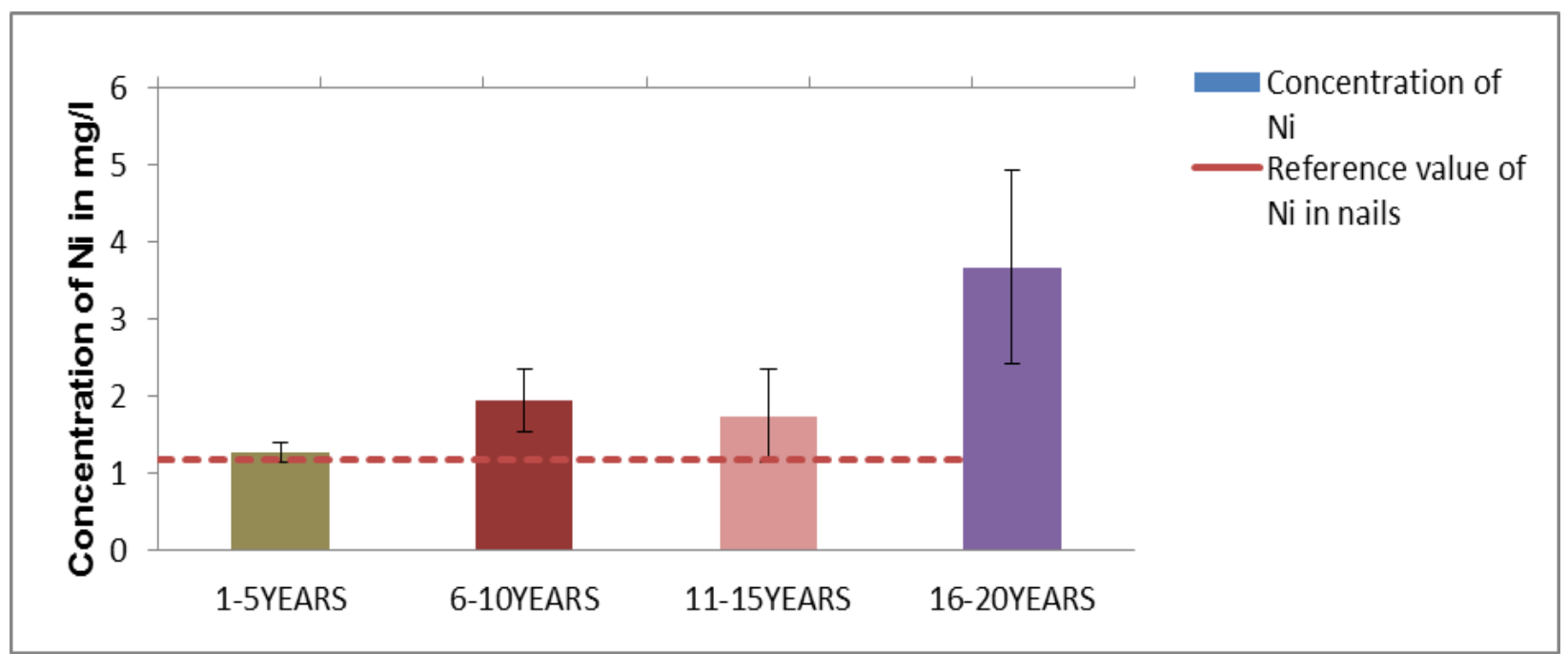

Figure 2. Comparison between the operational year and concentration of $\mathrm{Ni}$ in poultry farm workers

\section{Conclusion}

It was concluded from the study that in all age group the nickel concentration in nail samples was significantly high as compared to reference value. Direct relationship was found between the operational years of exposure and nickel concentration in nail samples. The workers were not aware of the importance of personal protective equipment (PPE) as these help workers in avoiding many accidents, injuries and disease. Moreover also recommended workers to implement healthy and hygienic lifestyle by taking bath daily, washing their hands after every processing and cut nail to avoid contamination. Reduce exposure to nickel during working hours by appropriate use of PPE so that the health problems caused by Ni could be avoided.

\section{Authors' contributions}

Conceived and designed the experiments: $M$ Abbas, Performed the experiments: A Abbas, Analyzed the data: M Abbas \& A Abbas, Contributed reagents/ materials/ analysis tools: A Zafar \& S Nosheen, Wrote the paper: M Abbas \& A Abbas.

\section{References}

1. Zhang HM, Deng GH, Feng TG \& Yang F (2013). Point Propagation Model of Pollution Sources of Heavy Metals in the Surface Soil. International Journal of Electrochemical Science 8: 5153-5160.

2. Thyssen JP, Carlsen BC \& Menné T (2008). Nickel sensitization, hand eczema, and loss-of-function mutations in the filaggrin gene. Dermatitis 9(6): 303307.

3. IPCS (1991). International Programme on Chemical Safety. Nickel. Geneva, World Health Organization, International Programme on Chemical Safety (Environmental Health Criteria 108).

4. EU (2004). Environmental Protection Agency for the European Union. Nickel sulphate risk assessment.

5. Rehman UK, Andleeb S, Mahmood A, Bukhar SM, Naeem MM \& Yousaf K (2012). Translocation of Zinc and Nickel from Poultry Feed to Broilers and Their Excretion Through Litters. Advances in Applied Science Research 2(3): 63-68.

6. Alkhalaf AN, KAO \& Salama AK (2010). Monitoring of aflatoxins and heavy 
metals in some poultry feeds. African Journal of Food Science 4: 192-199.

7. ATSDR (2005). Agency for Toxic Substance and Disease Registry. Toxicological Profile for Nickel.

8. Chervona Y, Arita A \& Costa M (2012). Carcinogenic metals and the epigenome: understanding the effect of nickel, arsenic, and chromium. Metallomics 4(7): 619-27.

9. Macomber L \& Hausinger RP (2011). Mechanisms of nickel toxicity in microorganisms. Metallomics. 3(11): 1153-62

10. Dara SS (2006). Trace elements: pollution and control. Textbook Environmental Chemistry and Pollution
Control. Chand and Company Ltd: New Delhi. 177-216.

11. Abdulrahman FI, Akan JC, Chellube ZM \& Waziri M (2012). Levels of Heavy Metals in Human Hair and Nail Samples from Maiduguri Metropolis Borno State, Nigeria. World Environment 4: 81-89.

12. Gammelgaard $B$, Peters $K$ \& Menno $T$ (1991). Reference values for the nickel concentration in human finger nails. Journal of Trace Elem 5: 121-123.

13. Abbas M, Rahman MA \& Safdar A (2012). Detection of heavy metals concentration due to leather tanning industry and prevelant diseases pattern in Kasur Pakistan. Environment and Urbanization Asia 3(2): 375-384. 